\title{
O TEXTO ENTRE A ENTEXTUALIZAÇÃO E A ETNOGRAFIA: UM PROGRAMA JORNALÍSTICO SOBRE BELEZAS SUBALTERNAS E SUAS MÚLTIPLAS RECONTEXTUALIZAÇÕES
}

\author{
Daniel Silva* \\ Universidade Federal do Estado do Rio de Janeiro \\ Rio de Janeiro, Rio de Janeiro, Brasil
}

\begin{abstract}
Resumo: Este artigo propõe um modo de leitura e análise de textos que considere, seriamente, o nexo linguagem-sociedade. Inscrito a um só tempo nas perspectivas pragmática e linguístico-antropológica, o artigo analisa um evento mediado - o Programa Profissão Repórter de 30/08/2011, que encenou, lado a lado, os concursos de beleza Miss Presidiária (Brasília), Miss Gay Brasil (Juiz de Fora) e Beleza Nordestina (Rio de Janeiro) - de forma a considerar o fato de que o evento não apenas entextualizou (i.e., fez viajar, nos termos de BAUMAN; BRIGGS, 1990) falas e imagens de outros contextos, mas também imaginou a trajetória de recepção do evento. Buscamos evidência etnográfica dos modos de produção e circulação do texto, a partir de observação participante com sujeitos que, de diferentes formas, receberam esse evento mediado.
\end{abstract}

Palavras-chave: Entextualização. Etnografia. Circulação de textos.

1 INTRODUÇÃO

O que a metáfora da viagem tem a nos ensinar sobre os textos? Dizemos frequentemente que certos "livros circulam mais do que outros", que "textos de divulgação científica extraem informação especializada e a fazem chegar até o leigo" ou que "peças de teatro viajam até nós desde a Grécia Antiga". Essa última expressão metafórica foi utilizada por Aderbal Freire-Filho no encarte que acompanha a peça "Jacinta". O espetáculo, que conta a história de Jacinta, a "pior atriz do mundo", interpretada por Andréa Beltrão, é assim descrito:

\footnotetext{
Jacinta, a peça, também fez uma longa viagem. Na verdade, viajar, viajar, viajar é o destino das peças de teatro, das boas peças de teatro. Algumas saíram da Grécia há séculos e viajaram até hoje e continuarão a viajar.

Como Jacinta é especialmente um poema que canta o teatro, sua viagem é múltipla, por fora e por dentro do teatro, um jogo de espelhos, que reflete sem parar suas imagens (FREIREFILHO, 2013, p. 2)
}

A descrição de Freire-Filho é em si um convite a um exame dos processos de textualização como uma viagem de signos. Para além de uma concepção de significação e textualização como transporte estável de significados, o autor da peça associa o fluxo dos textos teatrais à multiplicidade, apontando, de um lado, que as peças viajam há

\footnotetext{
* Professor Adjunto II da UNIRIO. Doutor em Linguística pela UNICAMP. Email: dnsfortal@gmail.com. 
muito tempo e, de outro, que a viagem implica jogos semióticos múltiplos. Obviamente, a viagem de um texto como Medeia, de Eurípedes, para os dias de hoje está envolvida em processos amplos de mudança pragmática e metapragmática: o uso dos signos (a pragmática) no "original" de Eurípedes e nas traduções contemporâneas certamente sofreu transformações, desde o uso das palavras em português moderno, que certamente diferem do uso em grego antigo; o entorno desse uso (a metapragmática) tem se transformado continuamente, desde o modo de se falar sobre essa peça até as múltiplas arregimentações do texto, e.g., sua divulgação "moderna" certamente difere da antiga em termos de suportes como a Internet ou a televisão ${ }^{1}$. No entanto, tanto no passado como hoje em dia, parece que viajar é de fato o destino dos textos.

Neste artigo, meu objetivo é discutir um modo específico de investigar o texto que leve em conta justamente a longa viagem que constitui os processos de textualização. $\mathrm{O}$ artigo seminal dos antropólogos da linguagem Bauman e Briggs (1990) nos chama a atenção para o fato de que compreender o texto e o discurso como performances demanda dos analistas não apenas uma atenção à intrínseca relação de textos com seus contextos ou sua contextualização (GUMPERZ, 1982), mas também à característica fundamental que os textos têm de se descontextualizarem. "Entextualização" foi o termo inventado por eles para capturar o processo contínuo e fundamental de tornar "um discurso extraível, de fazer de um trecho [stretch] de produção linguística uma unidade - um texto - que pode ser levada [lifted out] para fora de seu evento interacional" (BAUMAN; BRIGGS, 1990, p. 73). A entextualização é, assim, a própria viagem de um trecho ou excerto para além de seu contexto "original". Ela captura os sentidos da relativa autonomia das unidades linguísticas de se tornarem textos, no trânsito de um contexto a outro. Visto sob essa perspectiva, defendem Bauman e Briggs (1990, p. 73), "um texto é [...] discurso tornado descontextualizável." $\mathrm{Na}$ medida em que a entextualização é uma história natural do discurso - para recuperar o projeto de análise de textos de Silverstein e Urban (1996) -, ela "pode incorporar aspectos do contexto, de modo que o texto resultante carrega elementos de sua história de uso consigo" (BAUMAN; BRIGGS, 1990, p. 73).

A relativa autonomia dos textos não significa que o texto deva ser analisado como objeto autônomo. Embora a análise do texto como um objeto em si seja legítima para determinados propósitos, para muitos outros propósitos entender um texto como "autossuficiente" é congelar sua historicidade; essa postura pode, em último caso, nos impedir de entender como certos elementos textuais se tornaram "verdade", "mentira", "voz", "fato", "afeto" a partir de determinados regimes de circulação de discursos. Bauman e Briggs certamente se inspiraram no clássico ensaio "Os gêneros do discurso" de Bakhtin - e de fato o citam em vários momentos de seu artigo -, para quem "o enunciado é um elo na cadeia da comunicação discursiva de um determinado campo" (BAKHTIN, 2003 [1953], p. 296). Compreender um enunciado, assim, implica compreender o lugar desse elo na longa cadeia de suas múltiplas recontextualizações. Nos termos de Bakhtin, um enunciado não pode ser visto como um objeto completo em si mesmo, mas sim "como resposta aos enunciados precedentes de um determinado

\footnotetext{
${ }^{1}$ Retornaremos ao nexo pragmática-metapragmática a partir de Silverstein (1976, 1993 e 2004), no tópico 3.
} 
campo" (p. 297). Cada texto, cada trecho, cada enunciado "rejeita, confirma, completa, baseia-se neles, subentende-os como conhecidos, de certo modo os leva em conta" (p. 297).

Se o texto é um movimento, como investigá-lo então? Como embarcar em seu trânsito sem se perder em algum tipo de relativismo segundo o qual a significação seria um deslizar infinito que não permite a estabilização? Como capturar o movimento da entextualização sem recorrer a postulados universais que desconsiderem as características próprias das práticas situadas dos grupos sociais? Acredito que a resposta pode ser dada parafraseando-se Marcuschi (2002, p. 45): uma boa análise de um texto, que capture aspectos importantes do movimento de sua entextualização, demanda uma boa análise da prática comunicativa. Teoria linguística e teoria social-antropológica, assim, devem andar de mãos dadas, sob pena de se levar a cabo uma análise empobrecida da ancoragem social dos textos - e o reverso, uma análise empobrecida da ancoragem linguística do texto social, também é verdade para análises sociais que ignorem aspectos fundamentais sobre textualização desenvolvidos pela linguística, como, p. ex., as de Koch (2004), Marcuschi (2002), Cavalcante (2012) etc. ${ }^{2}$

Como sugere o título deste trabalho, minha posição é a de que uma análise de texto que recupere sua constituição mútua com a sociedade implica uma sensibilidade a processos de entextualização e a evidências etnográficas de como os atores envolvidos na prática comunicativa enquadram, recebem, respondem, refutam, enfim, como aderem às unidades linguísticas que se agruparam na forma de um texto. Não estou aqui reivindicando que linguistas se transformem em etnógrafos (o que não seria ruim, se aceitarmos que a linguística é uma ciência social), mas sim que tenham sensibilidade ou vigilância etnográfica em suas análises dos textos ${ }^{3}$.

Para ao mesmo tempo exemplificar e constituir minha posição, procederei à análise de como o programa jornalístico Profissão Repórter, dirigido por Caco Barcellos e exibido às terças-feiras às $23 \mathrm{~h}$ em rede nacional pela Rede Globo, recontextualizou ou entextualizou as falas de migrantes nordestinas na edição de 30 de agosto de 2011. Nesse dia, o programa exibiu três concursos de beleza, os quais encenavam corpos e belezas, por assim dizer, subalternos. Figuraram lado a lado três matérias: sobre o concurso Miss Presidiária, realizado em Brasília, o Concurso Miss Gay Brasil, em Juiz de Fora, e o Concurso Beleza Nordestina, no Rio de Janeiro. Tendo em vista que "práticas de textualidade e entextualização terminam sendo práticas sobre "identidade" (SILVERSTEIN; URBAN, 1996, p. 10), darei especial atenção à construção, naquele evento particular, de identidades subalternas, de modo geral, e de identidades

\footnotetext{
2 A literatura em antropologia linguística é repleta de críticas contundentes às análises de fatos linguísticos que desconsideram evidências sociais. Uma visão apurada dessas evidências muitas vezes invalida a suposta validade universal de algumas teorias, quando não as próprias teorias (ver ROSALDO, 1982, para uma crítica etnográfica à teoria dos atos de fala; KEENAN, 1976 e HAVILAND, 1997, para, respectivamente, a pragmática griceana e neogriceana; BRIGGS, 1997, para a análise da conversação; BOURDIEU, 1998, para o empreendimento estruturalista e gerativista, entre outros). Em português, um bom exemplo de equilíbrio entre análise linguística e social é Língua como prática social, de Hanks (2008).

${ }^{3}$ É uma aguçada sensibilidade etnográfica que norteia as belas e contundentes críticas de Helena Martins a poderosas teorias linguísticas (MARTINS, 2003) e filosóficas (MARTINS, 2012).
} 
nordestinas, de modo mais específico. Basearei minhas formulações em análise textual do programa e em etnografia realizada por meio de observação participante e entrevistas, com migrantes nordestino/as no Rio de Janeiro, jornalistas e outros agentes envolvidos na mediação daquele texto jornalístico.

\section{CAMPO}

Tenho conduzido, juntamente com os alunos Frederico Alt, Debora Ferrol e Anabella Rocha, desde 2010, pesquisa de campo com migrantes nordestinos ao Rio de Janeiro e São Paulo ${ }^{4}$ O projeto maior ${ }^{5}$ investiga a mediação da violência simbólica contra nordestinos nessas duas cidades. O presente texto, no entanto, não tem a intenção de investigar violência, apesar de se poder inferi-la em alguns aspectos da interação analisada a seguir. Selecionei para a presente análise notas de campo de visitas à Feira de São Cristóvão, bem como entrevistas com duas participantes do Concurso Beleza Nordestina, promovido pela Feira de São Cristóvão e Rede Globo, em 2011, além de outra entrevista sobre o papel da mídia, com uma jornalista que já trabalhou em diversos jornais da mídia corporativa. Utilizarei também notas de um grupo focal, realizado em São Paulo em 2013, em que discuti questões de subalternidade a partir dessa edição do programa, com estudantes universitários e professores de ciências humanas, alguns deles do Nordeste.

Na dinâmica da presente análise das entextualizações que culminaram na edição do Profissão Repórter de 30/08/2011 - doravante, texto-evento - e dos textos envolventes, como as entrevistas, o grupo focal e textos do blog do programa na Internet - doravante, textos-suplemento -, os dados "escritos" e "falados" significam tanto quanto os "silêncios". Tentamos, por telefone e por e-mail, entrar em contato com os jornalistas do Profissão Repórter - em especial com Caco Barcellos, o editor do programa -, mas um grande silêncio sucedeu-se às nossas tentativas. Mais eloquente foi a negação de Pará ${ }^{6}$ em conceder entrevista. Ele é o coordenador cultural da Feira de São Cristóvão e aparece na edição do texto-evento paramentado com gibão e chapéu de sertanejo, acompanhando efusivamente as participantes do concurso. Sua recusa a participar da pesquisa foi indireta, já que, quando o procuramos, ele nos disse para esperar, mas não aparecia. Taddei e Gamboggi (2012) comentam que a resistência ao encontro etnográfico é um fato marcante em muitos trabalhos de campo. Os autores contam que, na década de 1950, o antropólogo norte-americano Lambos Comitas seguiu para Barbados para um ano de etnografia sobre o obeah, prática religiosa de origem africana. Ao chegar lá, dirigiu-se ao único bar do vilarejo e foi informado pelo atendente de que não havia essa prática na comunidade. Frustrado, Comitas mudou seu tema de estudo para a pesca artesanal na região. Mais de um ano depois, às vésperas de partir, o

\footnotetext{
${ }^{4}$ Agradeço a Fred, Debora e Anabella pela parceria no campo e nas discussões teóricas e na cansativa porém necessária transcrição dos dados de fala. Sem eles, este trabalho não teria se realizado.

5 Trata-se do projeto "Mediação e circulação da violência simbólica contra nordestinos no Rio de Janeiro e em São Paulo”, financiado pela Faperj (Proc. E-26/110.679/2011).

${ }^{6}$ Com exceção dos nomes dos jornalistas do Profissão Repórter e dos participantes dos Concursos Miss Gay e Presidiária, os nomes das pessoas que participaram de nosso campo foram inventados, de forma a evitar potenciais riscos envolvidos com a divulgação de seu nome.
} 
mesmo atendente disse a Comitas que o sacerdote obeah era um homem que ambos viam frequentemente no bar, mas que não daria essa informação a qualquer forasteiro. Duas lições se pode tirar da experiência de Comitas. Uma delas é que, geralmente, os membros da comunidade estudada "estarão ocupados com seus problemas cotidianos e irão querer saber quem é o pesquisador, por que está ali, quais suas intenções e por que devem gastar seu tempo ajudando-o" (TADDEI; GAMBOGGI, 2012, p. 14). A outra é que, aos poucos, pesquisadores e membros da comunidade precisam desenvolver uma relação de confiança (p.13). Essas duas lições provavelmente derivam, dentre outros fatores, do processo de comodificação dos signos, que explicamos a seguir.

O silêncio dos jornalistas e a recusa indireta de Pará são significativos. Evitarei fazer generalizações sobre a relação entre mídia corporativa e universidade. Neste momento, tomarei esses silêncios como índice do mercado simbólico (BOURDIEU, 1998) de onde participam, desigualmente, pesquisadores, jornalistas e o coordenador cultural da feira, um índice que impacta o próprio dado. Teresa, a jornalista com quem conversamos e que trabalhou em grandes empresas da mídia corporativa, nos ofereceu uma boa explicação sobre como à informação se agrega valor no meio jornalístico - ou, dito de outro modo, como a entextualização, nessa esfera da atividade, se associa à comodificação de signos (BOURDIEU, 1998; AGHA, 2011):

\begin{abstract}
e isso é verdade da dificuldade de acesso... eu já trabalhei em jornais grandes e UMA COISA é eu ligar dizendo que sou do jornal Valor Econômico... ou da Folha de S. Paulo porque as pessoas te atendem com muito mais solicitude assim... do que eu ligar dizendo que eu sou freela... e que tô fazendo um trabalho para o site do/ sei lá/ Instituto Goethe/ que eu tô fazendo freela... AGORA... embora esse eu não precise falar nunca com organizações oficiais... são pessoas... mas esse menino contava essa história... que ele cobria energia... que ele precisava falar com algumas pessoas do governo sobre algum determinado assunto... daí ele sempre ligava e as pessoas diziam que a pessoa tava ocupada... não podia... ou qualquer desculpa... daí a pouco ele via a pessoa que ele tava procurando dando declaração sobre o assunto em/ ou no site da Globo... ou da Folha... do Estadão ou do Valor
\end{abstract}

O caso concreto relatado por Teresa se assemelha aos casos que experienciamos. Bourdieu (1998) argumenta que, contrariamente ao que Saussure e Chomsky postularam, a língua não é um "tesouro" livremente depositado na mente do falante (a metáfora é do próprio SAUSSURE, 1986 [1916], p. 21) - se, por um lado, a língua como fato social (para Saussure) ou biológico (para Chomsky) é um dado natural e universal, a partir do momento que a língua se torna uso, este é submetido à distinção, i. e., o "dado linguístico" vira imediatamente capital simbólico desigualmente distribuído na sociedade ${ }^{8}$. Assim, no relato de Teresa, a unidade linguística "informação sobre energia" foi mais facilmente "vendida", i.e., entextualizada, para os detentores do capital simbólico jornalístico, mas não para freelancers. O colega da jornalista ficou frustrado com o fato de a mesma pessoa, que indiretamente recusou seu pedido de entrevista, ter prontamente fornecido aquela informação para Folha, Estadão etc.

\footnotetext{
${ }^{7}$ Citaremos as falas com mais de três linhas seguindo uma adaptação simplificada de transcrições do texto oral (i.e., sem maiúsculas ou vírgulas, com caixa alta para ênfase). Quando essas falas viajam para o interior dos parágrafos, utilizaremos as convenções da escrita.

${ }^{8}$ Tomasello (2005) vai além e defende que a própria aquisição de linguagem é um processo cultural.
} 
A primeira formulação etnográfica sobre as modalidades de entextualização daquele texto-evento, assim, aponta para o fato de que o mesmo Pará, que performaticamente animava o concurso de miss no texto-evento, nos recebeu com indiferença. Os mesmos jornalistas que buscam cientistas para divulgar "em primeira mão" os avanços da ciência silenciaram diante de nosso pedido de entrevista. Embora nossa experiência em campo não seja suficiente para fazermos generalizações, ela aponta para o pouco prestígio da academia na entextualização de eventos da mídia. $O$ mercado simbólico tem regras não explícitas às quais temos chegado indiretamente, por meio de indícios.

\section{PROFISSÃO REPÓRTER E O NEXO PRAGMÁTICA-METAPRAGMÁTICA}

Profissão Repórter se apresenta como programa de jornalismo reflexivo. A equipe de Caco Barcellos faz reportagens e simultaneamente tece comentários sobre seus modos de fazer reportagens. Tomarei essa relação entre notícia e metanotícia para explicar o nexo pragmática-metapragmática, nos termos de Silverstein $(1976,1993)$, fundamental para entender a circulação dos signos.

Como não conseguimos falar com os jornalistas sobre o propósito do programa, restou-nos investigar a página do programa na Internet (g1.globo.com/profissãoreporter). Há no site uma breve descrição textual do programa: "Caco Barcellos e sua equipe de jovens repórteres mostram diferentes ângulos da mesma notícia." Apesar do breve texto, vídeos dos programas exibidos e "metavídeos" são abundantes. Estou chamando de metavídeos aqueles que divulgam ou refletem sobre o programa. No parágrafo seguinte, descreverei o vídeo "Profissão Repórter continua atrás da notícia em 2013” (GLOBO, 2013), que funciona como propaganda da temporada 2013.

$\mathrm{O}$ vídeo se inicia com Caco Barcellos, que fala enquanto se movimenta: "correr atrás da notícia, da história por trás da notícia". Superpõem-se a essa imagem outras de grandes aglomerados de pessoas em movimento. Sai de um metrô lotado a repórter Eliane Scardovelli, que fala: "Nas multidões". No meio de um conglomerado de pessoas no Oriente Médio, o repórter Caio Cavechini diz que "tem que chegar chegando". "Entrar aqui é bem complicado", diz Eliane Scardovelli enquanto tenta entrar no metrô apinhado. "Nas ruas", fala Thais Itaqui, ao atravessar a rua. "Estamos acompanhando um carro", diz Caco Barcellos. "Sempre em movimento", diz a jornalista Daniele França, numa avenida movimentada. "A gente está chegando aqui no meio do mato fechado", diz Victor Ferreira. "Como é que vamos caminhar com essa matéria?", pergunta Caco Barcellos ao seu grupo de repórteres. A conhecida voz masculina que anuncia os programas da Globo encerra o vídeo: "próxima terça, depois de Louco Por Elas, começa a nova temporada de Profissão Repórter".

Este vídeo projeta o modo de fazer reportagem do Profissão Repórter como um fluxo. Em sua primeira fala no vídeo, Caco Barcellos afirma que o programa corre atrás não apenas da notícia, mas também da "história por trás da notícia". Para ser considerada uma "história por trás da notícia", uma unidade linguística precisou ser descontextualizada e levada (i.e., entextualizada) para outro lugar, sendo assim posicionada como a história que "complementa", "confirma", "atesta", "refuta" o "fato" 
ou notícia. De forma a fazer um enunciado viajar, é necessário imaginar seu trajeto. Utilizando os termos de Silverstein (1993), essa imaginação do trajeto ou circulação de signos é um fenômeno metapragmático, que regimenta a pragmática desses mesmos signos. Parafraseando Caco Barcellos, precisamos caminhar com a definição do nexo pragmática-metapragmática.

Para Silverstein, pragmática é indexicalidade. Nos termos da semiologia de Peirce (1955 [1897]), o índice - o signo que indexa, indicia - mantém uma relação de coocorrência física ou contiguidade com seu objeto. Uma pegada na areia é um índice do pé (objeto) que pisou na areia: tanto o signo, a pegada, quanto o objeto, o pé, partilham de uma relação de contiguidade - o pé causou a pegada. Perceba que, nos termos de Peirce, embora a conexão entre índice e objeto seja "física" ou "contígua", essa conexão é mediada por um terceiro signo, o interpretante, que é uma espécie de operação mental ou tradução da relação semiótica (PARMENTIER, 1994). Assim, a pura fisicalidade do índice é, nos termos da filosofia de Derrida (1997 [1967]), adiada por um outro signo, o interpretante. Como todo uso de signo envolve um "contexto", então, necessariamente, todo uso de signo é contíguo a um contexto (e a um cotexto). $\mathrm{O}$ signo, assim, funciona como índice do contexto. Porém, além de pressupor um contexto, o signo cria o contexto. Resumindo, os signos, a um só tempo, pressupõem e criam seus contextos. Nas palavras do próprio Silverstein (1993, p. 36): o signo "pressupõe (portanto, indexa) algo do seu contexto-de-ocorrência, ou acarreta (e portanto indexa) algo sobre seu contexto-de-ocorrência".

$\mathrm{Na}$ visão de Silverstein, os signos que funcionam metapragmaticamente “enquadram", "regimentam", "estipulam" os fenômenos indexicais ou pragmáticos ${ }^{9}$. No vídeo descrito acima, o enunciado "como vamos caminhar com esta notícia?", dito por Caco Barcellos depois de uma sequência em que o jornalismo é projetado como fluxo, funciona metapragmaticamente. Esse enunciado retrospectivamente "modela" ou "enquadra" o uso dos enunciados e das imagens anteriores. É ele que define o caminho que a notícia deve seguir.

Pragmática e metapragmática funcionam numa dialética, ou, como diz Charles Briggs (2007, p. 332), as duas "andam de mãos dadas". Como vimos anteriormente, a relação que o signo estabelece com o contexto é a um só tempo de pressuposição e criação. O signo indexical projeta um contexto. E o signo metapragmático modela ou regimenta esse uso indexical. A noção de coerência textual (KOCH; TRAVAGLIA, 1990), por exemplo, é um conceito metapragmático. O modelo cognitivo de texto que os interlocutores constroem interacionalmente é uma representação do uso das unidades do texto e, portanto, uma metapragmática desse uso. Comenta Silverstein (1993, p. 3637) que, numa interação discursiva, "sem uma função metapragmática simultaneamente em jogo com a função pragmática (ou funções) não há possibilidade alguma de haver coerência interacional”.

\footnotetext{
${ }^{9}$ Um dado biográfico é importante aqui: Silverstein (1976) havia inventado o conceito de metapragmática num texto que "indexa" a invenção da noção de metalinguagem por Jakobson (1971[1957]). O ensaio de Jakobson intitula-se "Shifters, verbal categories, and the Russian verb". O ensaio de Silverstein, "Shifters, linguistic categories, and cultural description". Silverstein não apenas cria um paralelismo com o título e com as ideias de Jakobson - o conceito de metapragmática é uma releitura da noção de metalinguagem -, mas também dedica o artigo "For Roman Jakobson", num reconhecimento do trânsito de Jakobson na linguística e na antropologia de Chicago.
} 
A pragmática projeta. A metapragmática modela. $\mathrm{Na}$ medida em que essa dialética ocorre no texto, estamos aqui diante de uma pragmática da textualidade. É importante ter em mente que, para Silverstein, estudo do texto não se desvincula de estudo da práxis sociocultural. Essa pragmática da textualidade, além de andar lado a lado com uma metapragmática da textualidade, implica uma atenção ao elo linguagem e sociedade. Nas palavras de Silverstein (1993, p. 34-35):

está em questão aqui, particularmente, como conceitualizar não-metaforicamente o relacionamento entre textualidade linguística (caracterizada acima como uma ordem formal apta a ser transcrita) e aquilo que é compreendido sob a rubrica da práxis sociocultural - o estabelecimento, a manutenção e a renovação (transformação) das relações sociais nas sociedades, de forma interacional, situada contextualmente.

Este modo de "ler" o texto-evento e o próprio Profissão Repórter como um texto mediado (MARTIN-BARBERO, 2009; SILVA, 2012) pauta-se, assim, na consideração da dialética pragmática-metapragmática - uma dialética, diga-se de passagem, sobre a qual a equipe do programa se mostra consciente. A presente leitura ancora-se, sobretudo, na inelutável necessidade da consideração da práxis sociocultural na interpretação desse texto. Na seção seguinte, descreverei algumas partes do texto-evento significativas para esse argumento.

\section{BELEZAS SUBALTERNAS}

A edição do Programa Profissão Repórter de 30/08/2011 - o texto-evento apresenta, lado a lado, três reportagens. Caco Barcellos, Gabriela Lian e Victor Ferreira noticiam, respectivamente, o Concurso Miss Presidiária (Brasília), o Concurso Miss Gay Brasil (Juiz de Fora) e o Concurso Beleza Nordestina (Rio de Janeiro).

Caco Barcellos é quem apresenta a chamada dos três concursos no início do textoevento. Um excerto da fala de um consultor de moda, "miss sorri sempre", viaja junto com imagens de aulas de passarela e etiqueta na penitenciária. Depois, surge a imagem de uma clínica de estética, onde Junior, candidato a miss Gay Brasil, faz depilação de sua barba. "Tem que ser muito homem para querer ser mulher, não?", diz Junior, deitado, enquanto uma esteticista tira sua barba com cera. A repórter ri. "É a dor da morte", arremata. "Sacrifício" é o trecho de enunciado de Caco Barcellos que acompanha as imagens de Junior desfilando como Victoria X. Uma candidata declara que gastou 60 mil reais com seu vestido. "Na eleição do Miss Gay Brasil" é o trecho de fala que complementa o enunciado anterior de Caco Barcellos. Logo se compreende que o excerto viajou segundos à frente. Aparece então Pará, cantando uma música de forró. O enunciado "eu quero ver tua beleza nordestina", em melodia de forró, caminha junto com a sucessão de imagens de moças com vestidos de chita, tensas, na final do concurso Beleza Nordestina. "Dá pra ver que é menino?", pergunta Gabriela Lian a um rapaz que toma cerveja num bar situado na rua do concurso Miss Gay. A imagem de candidatas ao concurso, andando do outro lado da rua, acompanha a resposta do rapaz a Gabriela, "eu não sei nem se você é mulher!". A repórter ri. O foco da câmera viaja para o corpo de Gabriela. 
A descrição acima, que contempla apenas 1 minuto e 30 segundos do início do programa, oferece uma pista de como a entextualização é uma viagem complexa. Como meu objetivo não é fazer uma descrição minuciosa dos 40 minutos do multimodal textoevento, concentrarei a atenção em alguns temas que emergiram no mesmo texto-evento, como a função metapragmática dos "bastidores" (dos concursos e da notícia), bem como da ideia de invenção de identidades, ora explícita (e.g., na "confusão geográfica" que, segundo Lian, é o concurso Miss Gay), ora implícita (e.g., no modo como o Nordeste é encenado na Feira de S. Cristóvão).

\subsection{METAPRAGMÁTICA DOS BASTIDORES}

No início do texto-evento, após a chamada dos três concursos, Caco Barcellos anuncia: "os desafios da notícia, os bastidores da reportagem, agora no Profissão Repórter". Como apontei, o programa se apresenta como "jornalismo reflexivo". O anúncio de Caco Barcellos acima extrai sua coerência da possibilidade de os textos seguirem trajetos não lineares: a reportagem, nos termos de sua fala, tem "bastidores" (e, portanto, palco); seu fluxo não é de águas calmas, mas sim repleto de "desafios". Esse enunciado tem, assim, uma importante função metapragmática, na medida em que direciona a compreensão da pragmática da reportagem.

O programa jornalístico, de fato, teve acesso aos bastidores dos três concursos de beleza. Talvez a metapragmática mais explícita dos três bastidores seja a do concurso Miss Presidiária. Afinal, essa metapragmática se ancora no próprio papel disciplinante da instituição penal (FOUCAULT, 2007; GOFFMAN, 2001), que estabelece o controle dos corpos sem muito espaço para questionamento. As nove finalistas do concurso Miss Presidiária aparecem numa sala da prisão aprendendo a usar salto alto e a andar na passarela. Na verdade, elas já sabem andar de salto, mas, como explica Carla Lívio, presa por tráfico de drogas e assalto a mão armada, "são 3 anos sem usar salto", i. e., o salto é proibido na cadeia. Só tênis e chinelo de dedo são permitidos pela dura metapragmática prisional. Além do consultor de moda, para quem "miss sorri sempre", duas vencedoras de concursos de beleza são chamadas a ensinar técnica de desfile às garotas. Depois, entra na sala Sofia Rossi, consultora de boas maneiras, etiqueta e postura. "Muitas pessoas pensam que isso é coisa de madame, coisa de gente rica, mas na realidade não é", ensina a consultora a um público atento de belas detentas. "O beijo é uma coisa muito brasileira" é o enunciado seguinte de Sofia Rossi, posicionada ao lado de Caco Barcellos. Ele será o aluno de Sofia um segundo depois. "Você vem tentar me dar um beijo no rosto e eu vou te segurar, tá?", diz a professora. Caco Barcellos consente e segue em direção a Sofia. "Tudo bom?", diz a consultora, estendendo a mão ao "aluno". "Tudo", diz Barcellos, que tenta beijar o rosto da professora. Ele é parado por um forte aperto em sua mão, que o impede de chegar mais próximo de Sofia. Todos riem. A cena viaja da sala da prisão para um corredor, onde as presidiárias andam em fila, "de cabeça baixa", conforme anuncia a voz de uma agente penitenciária. "Do lado de fora da sala de ensaio, o mundo de miss não existe", diz Caco Barcellos, em voiceover. "Acabado o treinamento, elas vão ser submetidas a uma revista, é isso?", pergunta o jornalista à agente prisional, ao lado das detentas. Vale ressaltar que as detentas são 
forçadas a mudar seu modo de usar o corpo de um ambiente a outro. Caco Barcellos, no entanto, permanece o mesmo jornalista, tendo igual acesso aos dois regimes metapragmáticos: o regime da sala de aula e o do corredor. Assim, esse programa de jornalismo se posiciona como aquele que está, a um só tempo, dentro e fora da prisão, dentro e fora da rígida metapragmática prisional.

Nos parágrafos precedentes, tentei descrever os modos como enunciados viajam de um contexto a outro, atravessando imagens, escalas, palcos, bastidores e culminando numa política de voz e verdade. Assim, a dinâmica da entextualização - a prática de retirar um texto de um contexto e levá-lo a outro - não é tão somente um processo multimodal de textualização, mas sobretudo uma dinâmica de poder. Como argumenta Blommaert (2008, p. 107), "nem todo contexto é/está acessível a todos, e práticas de (re)entextualização dependem de quem tem acesso a qual espaço contextual". Como discutimos na seção 2, nós, professor e alunos da universidade, não tivemos acesso ao espaço contextual da Rede Globo nem ao da Feira de S. Cristóvão (pelo menos ao espaço de interseção entre a Feira e a Globo, iconizado por Pará), o que aponta para o acesso desigualmente distribuído ao poder de entextualizar. Retornarei a este fundamental ponto abaixo. Antes, avancemos na invenção de identidades.

\subsection{INVENÇÃO DAS IDENTIDADES}

Ao passo que a reportagem de Gabriela Lian concede espaço à multiplicidade das identidades no concurso Miss Gay Brasil, Victor Ferreira apresenta uma festa das identidades essencializadas no Concurso Beleza Nordestina. Conforme discutirei nas seções seguintes, há evidências etnográficas de que esse espetáculo essencializado não é recebido da mesma forma pelos sujeitos com quem conversamos: as participantes do concurso não se importaram com o modo como sua fala e imagem foram entextualizadas, talvez porque seu interesse pelo concurso era sobretudo econômico; mulheres e homens do Nordeste e de outras partes do Brasil, que leram o programa de forma crítica, não aceitaram tranquilamente a política de entextualização do textoevento. Vejamos uma breve descrição dos modos de apresentação das duas reportagens.

Como vimos, Gabriela Lian, ao cobrir o Miss Gay Brasil, tem sua própria identidade de gênero questionada. Para se referir às participantes, a repórter tem de oscilar entre os pronomes pessoais "ele" e "ela". Júnior, que concorre ao Miss Gay como Sheila X, explica a Gabriela: "Eu sou um ator transformista. Então tudo isso é maquiagem, é peruca, são acessórios que me fazem tornar a Sheila. Mas eu sou o Júnior. Minha identidade é masculina, independente de minha orientação sexual." Como aponta Rajagopalan (2003), as identidades são reivindicadas para fins estratégicos, embora a "estratégia" não seja inteiramente consciente ou intencional. Nos termos do presente artigo, é o encontro interacional, com sua dinâmica de poder, que determina os posicionamentos identitários (e é retrospectivamente por eles determinado): Júnior tinha diante de si uma metapragmática que o obrigava a ser Júnior de dia e Sheila $\mathrm{X}$ à noite, conforme o comentário metapragmático de Michelly X, a organizadora do concurso: "o concurso é de transformista. Então a pessoa tem de ser um rapaz de dia. Não pode fazer uso de hormônios, prótese, cirurgia plástica, uso de hormônios, entendeu?”. 
Parafraseando Bakhtin (2003 [1953]), o enunciado de Júnior/Sheila X, assim, é uma resposta ao enunciado de Michelly X. Toda identidade é uma resposta a algum enunciado.

$\mathrm{Na}$ reportagem, a ausência de uma base fundacional para as identidades é complementada pela viagem interestadual das candidatas a miss. Enquanto uma animação mostra a viagem de candidatas a miss sobre um mapa cor de rosa do Brasil, margeado por um oceano da cor da bandeira do arco-íris, narra a jornalista:

O Miss Brasil Gay é uma verdadeira confusão geográfica. Enquanto a paulista Victoria representa os gaúchos, a carioca Sheila representa os paulistas. A alagoana Bianca representa os capixabas. A mineira Raika representa o Piauí. E Martinela saiu de São Paulo, tentou o concurso do Paraná, do Distrito Federal e virou miss Goiás.

Não apenas os signos viajam, mas também as identidades.

A reportagem de Victor Ferreira, por outro lado, investe nos estereótipos e na indivisibilidade. Victor inicialmente reporta a apresentação das candidatas aos jurados, os quais se vestem em estilo "urbano", com exceção de Pará, paramentado de cangaceiro. No dia em que encontramos Pará na Feira, ele estava em estilo "urbano". Surge na reportagem a imagem de Pará. "Além de cantor de Forró, Pará é jurado", diz Victor, enquanto Pará retira os óculos redondos, iteração do óculos de Lampião, para olhar para as garotas. "Um trabalho assim eu queria ter todo dia e toda hora. Escolher as Marias Bonitas do Brasil e da Feira de São Cristóvão", confessa o jurado para o microfone da Globo. Na cena seguinte, as candidatas estão tirando medidas para a confecção do vestido que ganharão da Feira. Uma candidata se mostra incomodada com a filmagem. Ela lamenta que "o mundo inteiro vai saber as [suas] medidas." Victor insiste em perguntar as medidas da garota, que responde com um ríspido "para!”. Após a medição, ela ri timidamente, enquanto sai da sala dizendo "tchau". Victor responde com um irônico "tchau". Ela esbarra na porta e sai cambaleante. A televisão não perde a oportunidade de entextualizar essa imagem. Descobriríamos na investigação de campo que as garotas assinaram um contrato de cessão de imagens por um ano para a Globo, copromotora do concurso. Victor foi um dos jornalistas que nos respondeu com um silêncio.

A escolhida de Victor para a reportagem de bastidores foi Lucy, uma pernambucana que migrara para o Rio havia pouco tempo, para estudar teatro e tentar uma carreira de atriz. A reportagem vai até a casa de Lucy, para mostrar o pequeno apartamento onde mora. "Lucy mora sozinha com um irmão no Rio de Janeiro", fala Victor, em voice-over, sobre uma imagem em que diz "muito prazer" à mãe de Lucy. "Mas trouxe a família toda de Pernambuco para as finais do Concurso Beleza Nordestina", complementa, enquanto o pai de Lucy toca violão e a mãe prepara o almoço. "Vocês chegaram na hora certa, para comer um sarapatel que minha mãe trouxe de Pernambuco", diz Lucy, dando ênfase à palavra 'Pernambuco'. Victor pergunta: “o que é sarapatel?", indexando sua diferença regional. "Sarapatel é miúdo de bode, são vísceras, né?", responde a mãe de Lucy. A dinâmica das entextualizações, em seguida, migra para o tema da saudade: "no começo eu sofri muito, chorava muito de saudade. 
Só depois de 6 meses é que ficou mais fácil”, conta Lucy, sentada no sofá da sala. "Você acha que o concurso pode te ajudar, na tua carreira?", pergunta Victor. "Acho que sim. Tem uma visibilidade, tem várias pessoas vendo. E é uma experiência né, nunca tinha participado de um concurso de beleza", responde, nos últimos momentos em que a televisão foca sua sala. A imagem passa então para a semifinal do concurso, na Feira. Victor tem trânsito livre para o camarim: "eu sou o único homem aqui". Logo corrige: "e o Wellington [o câmera] também", sorrindo desconcertado. Dentro do camarim, ele demonstra seu poder, sugerindo que uma candidata prenda o cabelo, em vez de deixá-lo solto. "Eu gosto mais preso", diz ele, enquanto Janaina Almeida é penteada por uma cabeleireira. "Tá bom então, ele é homem" responde rapidamente a candidata, que é logo interrompida por Victor: "você vai na minha?". Ela não pensa duas vezes: "Eu vou na sua, vamos, pode prender", diz ela à cabeleireira, nessa rápida cena de dupla submissão ao poder masculino e televisivo. O repórter arrisca palpites de quem irá vencer, até que a imagem viaja até o pátio da Feira.

Chega a vez de Lucy desfilar. Victor pergunta a Pará se ele está animado com o desfile. “Tu já viu o tanto de mulher bonita que tem hoje aí?", é a resposta em forma de pergunta que oferece Pará, indexando que sua ideologia masculinista pode encontrar resposta do outro lado. No bloco seguinte, o texto-evento exibe a final. "Vamos chamar em primeiro lugar... Lucimara Souza" é o enunciado que se escuta de uma voz feminina, enquanto as candidatas aparecem tensas, no palco da Feira. "Lucimara Souza, que é do Nordeste, ganhou 5 mil reais, e uma viagem para o Nordeste. A baiana foi pra Fortaleza", arremata Victor, enquanto fotos de Lucimara nas praias do Ceará se superpõem à narração de Victor. Este último trecho, que fizemos viajar até o grupo focal de São Paulo, foi recebido com risos, dada a circularidade do prêmio.

Como bem sintetiza Blommaert (2008, p. 107), “a dinâmica de entextualização claramente nos leva de volta a questões de acesso diferenciado aos recursos de poder e, portanto, nos leva diretamente à estrutura social". É precisamente a estrutura social que se mostra no relato etnográfico a seguir. Discutirei como o diálogo com a perspectiva nativa, produtora de alguns dos assim chamados textos-suplemento, nos ajudou a compreender a construção não apenas do texto-evento, mas também de sua política de voz e verdade.

\section{LUCY, LUCIMARA E A LUTA PELA ENTEXTUALIZAÇÃO}

Em 10 de dezembro de 2012, finalmente sentamos no Café da Livraria da Travessa no Centro do Rio de Janeiro para entrevistar Lucimara. Já fazia mais de um ano que ela havia vencido a edição de 2011 do concurso Beleza Nordestina. Desencontros de várias ordens haviam frustrado nossas tentativas anteriores de conversar com essa baiana que migrou para o Rio de Janeiro com 8 anos de idade e que não se identifica com Salvador, nem com o sotaque da cidade. No final, o lastro de tempo de mais de um ano que separou este encontro e a entrevista com Lucy, a pernambucana que ficou entre as 16 finalistas do concurso, se mostrou positivo. Como descobriríamos depois, o trabalho do tempo nos teria dado não só maturidade teórica; ele daria a Lucimara a chance de participar do júri da edição de 2012 do mesmo 
concurso, e a nós, a oportunidade de compreender um pouco melhor o modo como a mídia "constrói" os fatos que "noticia", o que, na seção 3, estudamos como o duplo funcionamento de pressuposição e criação do "contexto", envolvido em todo uso pragmático de um signo. O diálogo a seguir acontece em resposta à pergunta "como foi participar do concurso":

Lucimara - é legal né? são coisas diferentes.. nunca tinha acontecido... gostei... devia ter mais... esse ano o miss beleza nordestina não teve muita... como é que eu posso dizer? éhh... não teve divulgação... foram inscritas só 100 meninas... acho que foi $60 .$. e não teve tanto sucesso quanto na primeira edição né? mas acho que foi falta de divulgação mesmo

Fred - você acha que de repente na primeira... como eles já tinham intenção do programa... então fizeram mais divulgação?

Lucimara - pode ter sido isso... porque esse ano eu acompanhei e fui até jurada na final... e não teve repórter... não fizeram matéria... só uma passagem rápida que teve no RJ TV

Daniel - e não tava aparecendo como promoção da Globo? porque o primeiro tinha uma coisa de "promoção Rede Globo"

Lucimara - teve teve... brindes... entregaram brindes... mas nada muito/

Daniel - então você achou que não foi tão divulgado/ tão cheio e badalado quanto foi o primeiro né? porque o primeiro devia ter tipo repórteres e câmeras sempre

Lucimara - e a gente gravou até com a Maria né? porque a Maria tava fazendo uma montagem pra Ana Maria Braga... e quando a gente recebesse o prêmio no palco a gente tinha que descer e ficar acompanhando ela em algumas/ alguns restaurantes nordestinos... não sei se você chegou a ver a matéria?

Antes de qualquer observação, é importante reconhecer as formulações de Lucimara como parte de um encontro interacional. Ela estava diante de pesquisadores interessados em sua participação no texto-evento. Uma estrutura social faz parte dessa cena, e isso é um fator que não se pode desconsiderar. Como em qualquer evento pragmático, o que Lucimara nos disse era o que podia ser dito, dada a contingência social do encontro (MEY, 2001). Lucimara inicialmente nos diz que o concurso de 2012, ao contrário do concurso anterior, "não teve divulgação". Logo depois ela diz que não "teve tanto sucesso quanto na primeira edição". Assim, o sucesso dos eventos foi diretamente proporcional à participação da mídia na produção e divulgação. No ano de 2011, não foi apenas o Profissão Repórter, mas também o programa de Ana Maria Braga que teve "interesse" pelo evento. Em outro momento da entrevista, ela complementa: "enquanto a gente estava no camarim se preparando sempre vinha alguém, veio o pessoal do esquenta, veio várias pessoas pra fazer entrevista pra vídeo, pra áudio, essas coisas." Em 2012, tudo o que houve foi uma "passagem rápida no RJ TV". Acreditamos que esse é um dado importante sobre a construção do fato jornalístico pela mídia, que muitas vezes patrocina o próprio evento que será noticiado.

Lucy elabora uma narrativa sobre o poder da mídia na construção da realidade social. Havíamos perguntado a ela se o programa tinha feito "bom uso [das entrevistas com ela] na televisão". Ela achou que sim, apesar de alguns erros:

tiveram alguns erros na edição, como falar assim... 'Lucy mora com seu irmão' e colocaram minha foto com o meu namorado... mas moro com o meu irmão e meu namorado... foram coisas muito bestas sabe? 
Depois, Lucy, que é estudante de teatro, elabora um discurso interessante sobre o poder que a televisão tem (de entextualizar):

\begin{abstract}
nisso tudo eu pude perceber uma coisa... o poder que a televisão tem de mudar o que ela quiser... eu falei "gente... foi uma coisa besta num programa que passa uma vez na semana... com erros bestas que não fizeram mal a ninguém"... a mim não fizeram mal nenhum... mas por exemplo... um programa... um reality show... como tudo pode ser manipulado... o que eu fiquei meio abismada foi com isso... olha o poder que uma TELEVISÃO TEM... o que uma edição não PODE FAZER... mas que no meu caso não foi prejudicial... mas que em outros casos eu não sei
\end{abstract}

Uma vez que citar, entextualizar, enquadrar, enfim, construir texto é um processo que acontece socialmente, dentro de regimes metapragmáticos específicos, o poder da mídia é talvez uma instância do poder envolvido na entextualização de forma mais ampla. Nos termos de Teresa, a mídia faz parte de um "mercado". A jornalista nos conta que, nos tempos de graduação, achava que "os veículos de comunicação eram acima de qualquer suspeita", mas depois, na prática, "caiu o mito". Depois de passar por centros de poder diversos e por diferentes veículos da mídia corporativa, ela nos diz que "pass[ou] a ver de outro jeito, porque é uma indústria, uma empresa como outra qualquer. Sem essa aura que [ela] colocava. É como outra qualquer que tem que dar lucro. Basicamente isso: tem que dar lucro."

Se Bourdieu (1998) estava certo ao propor que a língua seja entendida como um mercado, o lucro da mídia corporativa precisa ser situado na busca mais ampla por lucro na prática comunicativa. Não se trata aqui de redimir a manipulação jornalística, mas, antes, de situá-la na ativa construção da realidade social em que nos envolvemos por meio das entextualizações nossas de cada dia.

Aqui, o ponto mais importante é o de que investigar (etnograficamente) a entextualização nos impede de construir dicotomias do tipo "a mídia é inerentemente má" e "a população é de partida manipulada". Ao contrário dos comentários dos participantes do grupo focal - para os quais nos voltaremos abaixo -, Lucy e Lucimara se mostraram satisfeitas com o modo de entextualizar suas falas e com a forma mais ampla em que foram apresentadas. O interesse das duas, afinal, era encontrar no concurso algum tipo de oportunidade. Certa noção de beleza racializada surgiu na entrevista com Lucimara:

Daniel - como é que foi tudo? ver que você ganhou e tal?

Lucimara - assim... até então eu não acreditei que eu ia ganhar

Daniel - por que você não acreditava?

Lucimara - eu não acreditava em mim... tinha meninas muito bonitas e tal... mas quando anunciou o segundo lugar... que ele ia anunciar meu nome... parecia que eu já sabia que era eu... mas assim... foi tudo muito novo... eu gostei... foi ótimo... aí eu ganhei uma viagem né? pro Nordeste... escolhi Fortaleza...

Daniel - tá... e você acha que... de repente... eles tendo escolhido uma candidata negra ajuda a quebrar um pouco o preconceito... as pessoas enxergarem mais a beleza negra?

Lucimara - sim né? tivemos até uma miss negra não foi? acho que agora tá mais natural... ser negra agora é uma raridade... tipo... uma pessoa bonita negra hoje em dia é privilégio 
Assim, Lucimara, que havia dito antes ter "vir[ado] baiana depois do concurso", afirma que passou a se ver como uma bela moça negra depois da competição. A exemplo de qualquer identidade, sua identidade negra e nordestina é emergente. A noção de beleza presente no último turno do excerto acima, porém, não aterrissou de forma tranquila no grupo focal. Nina, uma moça pernambucana, militante de direitos negros, pediu-me para contextualizar a fala de Lucimara. Do modo que está dito, o enunciado tem implicações racistas, do tipo é 'raro encontrar uma pessoa negra bonita'. Talvez a polidez do evento tenha impedido que Nina elaborasse mais sobre o racismo que parece viajar junto com esse enunciado, porém sua pergunta funcionou como um ato de fala indireto de crítica. Polida também foi a forma como Marília, que é de Mato Grosso, reclamou dos estereótipos presentes no concurso Beleza Nordestina, um incômodo que não percebemos na fala das duas participantes que entrevistamos.

Menos polidas foram as palavras de Kátia, uma professora do Piauí que assistiu conosco ao texto-evento, para quem "o programa como um todo é uma forma de preconceito. Os nordestinos só são belos depois das $23 \mathrm{~h}$, junto das presidiárias e dos gays". A mãe de Lucy havia feito um comentário semelhante. A participante do concurso reporta as palavras da mãe: "É, botaram o Nordeste bem, né? As presidiárias, os gays e o Nordeste.” Perguntei o que ela achou disso. A resposta de Lucy foi:

\footnotetext{
no começo eu achei 'nossa botaram bem como minorias mesmo'... mas eu não vejo problema porque os concursos em si não eram ligados... não tinha nada a ver... foi meio que o caráter do programa que eles escolheram... mas eu acho bom porque eu não achei que o programa foi de forma pejorativa... achei tranquilo
}

Ou seja, apesar do incômodo de sua mãe em ver o Nordeste sendo posicionado junto de outras minorias, a posição de Lucy vai "sendo feit[a], refeit[a], transformad[a], reformad[a] etc. no processo de tempo real da interação discursiva" (SILVERSTEIN, 1993, p. 38). Sua opinião decola de um incômodo, passa por uma desidentificação (os concursos não eram ligados) e aterrissa na visão de que o programa não foi pejorativo. Lucimara, sempre breve em suas respostas, respondeu com um "não" quando perguntei se ela teve uma impressão ruim em ver os três concursos lado a lado. "Você ouviu algum comentário preconceituoso?", insisti. Novamente, "não" foi a resposta.

Os múltiplos posicionamentos que lemos no parágrafo anterior sobre o modo que as pessoas (se) viram (n)o posicionamento do Nordeste ao lado do Presídio e da Homossexualidade são um bom índice de quão heterogênea e complexa é a nossa adesão aos signos. Um mesmo sujeito, como Lucy, vai refazendo, "no tempo real da interação", seu posicionamento diante da questão das minorias. Lucy, consecutivamente, adere e não adere à diferença dos outros dois concursos. Tanto a mudança "em tempo real" da opinião de Lucy quanto a luta pela entextualização que aconteceu no grupo focal - e cujos ecos ouvimos nas vozes de Nina, Kátia e Marília são alguma evidência etnográfica de que é complicado afirmar que "haja um mundo social diferenciado, existindo antes dos processos de entextualização" (SILVERSTEIN; URBAN, 1996, p. 6). Arriscamos que a luta "pelo domínio dos processos de contextualização" (FABRÍCIO, no prelo) tem um potencial analítico ímpar na compreensão da mudança social. Como formulam Silverstein e Urban (1996, p. 6), "categorias sociais, se legíveis de processos de entextualização, são igualmente produto deles." 
Acredito que este artigo fornece evidência etnograficamente situada de que o texto se constitui na viagem das unidades linguísticas e multimodais. Trata-se de uma viagem repleta de momentos de calmaria e turbulência. A tese em si não é nova; podemos ler essa visão de signo e de texto como fenômenos em constante fluxo e mudança nos textos seminais de Voloshinov e Bakhtin. Minha principal tese, no entanto, é a de que uma atenção de fato deve ser dada à estrutura social na leitura do texto. $\mathrm{O}$ caminho que apontei para a consideração do laço texto-sociedade foi a etnografia, que permitiu um diálogo com a perspectiva daqueles que estão envolvidos no processo de mediação, desde aqueles que produziram o texto ou textos daquele tipo (Teresa), passando pelos agentes representados pelo texto (Lucy e Lucimara), até a sua recepção (o grupo focal). Mas reconheço que há muitos outros caminhos de dialogar com a sociedade na leitura (e análise) do texto. Espero que mais pesquisas produzam evidência interacional para dialogar com a nossa, para confirmá-la, refutá-la, reformá-la. Afinal, este texto, como qualquer outro, espera por resposta na durável luta pela entextualização.

\section{REFERÊNCIAS}

AGHA, A. Meet mediatization. Language \& Communication, v. 31, p. 163-170, 2011.

BAKHTIN, M. Os gêneros do discurso. In: Estética da criação verbal. São Paulo: Martins Fontes, p. 261-306, 2003 [1953].

BAUMAN, R.; BRIGGS, C. Poetics and performance as critical perspectives on language and social life. Annual Review of Anthropology, v. 19, p. 59-88, 1990.

BLOMMAERT, J. Contexto é/como crítica. In: SIGNORINI, I. (Org.) Situar a lingua(gem). São Paulo: Parábola, 2008, p. 91-115.

BOURDIEU, p. A economia das trocas linguísticas. São Paulo: Edusp, 1998.

BRIGGS, C. Notes on a "confession": On the construction of gender, sexuality, and violence in an infanticide case. Pragmatics, v. 7, n. 4, p. 519-546, 1997.

Mediating infanticide: Theorizing relations between narrative and violence. Cultural Anthropology, v. 22, n. 3, p. 315-356, 2007.

CAVAlCANTE, M. Os sentidos do texto. São Paulo: Contexto, 2012.

DERRIDA, J. Of grammatology. Baltimore: John Hopkins University Press, 1997 [1967].

FABRÍCIO, B. F. Transcontextos educacionais: gêneros e sexualidades em trajetórias de socialização na escola. In: SILVA, D.; FERREIRA, D.; ALENCAR, C. (Orgs.). Nova pragmática: modos de fazer. São Paulo: Cortez, no prelo.

FOUCAULT, M. Vigiar e punir. Petrópolis: Vozes, 2007.

FREIRE-FILHO, A. Jacinta, a peça. Rio de Janeiro: Teatro Poeira/Petrobrás, 2013.

GLOBO. Profissão repórter continua atrás da notícia em 2013. Vídeo disponível em: $<$ http://g1.globo.com/profissao-reporter/videos/t/programas/v/profissao-reporter-continua-atras-danoticia-em-2013/2483044/>. Acesso em: 9 abr. 2013.

GOFFMAN, E. Manicômios, prisões e conventos. São Paulo: Editora Perspectiva, 2001.

GUMPERZ, John. Discourse strategies. Cambridge: Cambridge University Press, 1982.

HANKS, W. Língua como prática social: das relações entre língua, cultura e sociedade a partir de Bourdieu e Bakhtin. São Paulo: Cortez, 2008.

HAVILAND, J. Shouts, shrieks, and shots: Unruly political conversations in indigenous Chiapas. Pragmatics, v. 7, n. 4, p. 547-574, 1997. 
JAKOBSON, R. Shifters, verbal categories, and the Russian verb. In: Selected writings of Roman Jakobson, v. 2. The Hague: Mounton, 1971 [1957].

KEENAN, E. O. On the universality of conversational implicatures. Language in Society, v. 5, n. 1, p. 6780.

KOCH, I. Introdução à linguística textual. São Paulo: Martins Fontes, 2004.

KOCH, I; TRAVAGLIA, L. A coerência textual. São Paulo: Contexto, 1990.

MARCUSCHI, L. Do código para a cognição: o processo referencial como atividade criativa. Veredas, v. 6, n. 1, p. 43-62, 2002.

MARTIN-BARBERO, J. Dos meios às mediações: comunicação, cultura, hegemonia. Rio de Janeiro: Ed. da UFRJ, 2009.

MARTINS, H. Sobre a noção de 'linguagem do pensamento' no paradigma experiencialista. Veredas, v. 10, p. 75-90, 2003.

Tradução e perspectivismo. Revista de Letras, n. 85, p. 135-149, 2012.

MEY, J. Pragmatics: an introduction. London: Blackwell, 2001.

PARMENTIER, R. Signs in society. Bloomington: University of Indiana Press, 1994.

PEIRCE, C. Logic as semiotic: the theory of signs. In: BUCHLER, J. (Org.) Philosophical writings of Peirce. New York: Dover Publications, 1955 [1897].

RAJAGOPALAN, K. Por uma linguística crítica. São Paulo: Parábola, 2003.

ROSALDO, M. The things we do with words: Ilongot speech acts and speech act theory in Philosophy. Language in society, v. 11, n. 2, p. 203-237, 1982.

SAUSSURE, F. Curso de Linguística Geral. São Paulo: Cultrix, 1986 [1916].

SILVA, D. Pragmática da violência: o Nordeste na mídia. Rio de Janeiro: 7 Letras/Faperj, 2012.

SILVERSTEIN, M. Shifters, linguistic categories, and cultural description. In: BASSO, K.; SELBY, H. Meaning in Anthropology. Albuquerque: University of New Mexico Press, p. 11-55.

Metapragmatic discourse and metapragmatic function. In: LUCY, J. (Org.) Reflexive language: Reported speech and metapragmatics. Cambridge: Cambridge University Press. 1993, p. 33-58. 639,2004

Cultural Concepts and the Language-Culture Nexus. Current Anthropology, v. 45, n. 5, p. 638-

SILVERSTEIN, M; URBAN, G. The natural history of discourse. In: (Orgs.). Natural histories of discourse. Chicago: University of Chicago Press, 1996, p. 1-17.

TADDEI, R.; GAMBOGGI, A. L. Etnografia, meio ambiente e comunicação ambiental. Caderno Pedagógico, v. 8, n. 2, p. 9-28, 2011.

TOMASELLO, M. Constructing a language: A usage-based theory of language acquisition. Cambridge, Mass: Harvard University Press, 2005.

\title{
Recebido em 26/04/13. Aprovado em: 07/02/14.
}

Title: The text between entextualization and ethnography: a media news event on subaltern beauties and their multiple recontextualizations

\begin{abstract}
Author: Daniel Silva
Abstract: This article puts forth a methodology for reading and analyzing texts that seriously considers the language-society nexus. Inscribed at once in the pragmatic and linguistic-anthropological perspectives, the article analyzes a mediated event-namely, the Profissão Reporter TV show of Aug. 30, 2011, which enacted, side by side, the beauty contests "Miss Presidiária" (Brasilia), "Miss Gay Brasil" (Juiz de Fora) and "Beleza Nordestina" (Rio de Janeiro) - so as to consider the fact that the event not only entextualized (i.e., caused to travel, in terms of BAUMAN; BRIGGS, 1990) talk and images from other contexts, but also imagined the trajectories of reception of the event. We looked for ethnographic evidence of the modes of production and circulation of the text, from a participant observation with subjects who variously received such mediated event.
\end{abstract}

Keywords: Entextualization. Ethnography. Circulation of texts.

SILVA, Daniel. 0 texto entre a entextualização e a etnografia: um programa jornalístico sobre belezas subalternas e suas múltiplas recontextualizações. Linguagem em (Dis)curso - LemD, Tubarão, SC, v. 14, n. 1, p. 67-84, jan./abr. 2014. 
Título: El texto entre la entextualización y la etnografia: un programa periodístico sobre bellezas subalternas y sus múltiples recontextualizaciones

Autor: Daniel Silva

Resumen: Ese artículo propone un modo de lectura y análisis de textos que considere, seriamente, el nexo lenguaje-sociedad. Inscrito a un sólo tiempo en las perspectivas pragmática y lingüístico-antropológico, el artículo analiza un evento mediado - el Programa Profissão Repórter de 30/08/2011, que escenificó, lado a lado, los concursos de belleza Miss Condenada (Brasília), Miss Gay Brasil (Juiz de Fora) y Belleza Nordestina (Rio de Janeiro) - de manera a considerar el facto de que el evento no sólo entextualizó (i.e., hice viajar, en los términos de BAUMAN; BRIGGS, 1990) hablas e imágenes de otros contextos, pero también imaginó la trayectoria de recepción del evento. Fue buscada evidencia etnográfica de los modos de producción y circulación del texto, a partir de observación participante con sujetos que, de diferentes maneras, recibieron ese evento mediado.

Palabras-clave: Entextualización. Etnografía. Circulación de textos. 